\title{
Odontogenic tumors: clinical and pathology study of 238 cases
}

\section{Rafael Linard Avelar', Antonio Azoubel Antunes', Thiago de Santana Santos ${ }^{3}$, Emanuel Sávio de Souza Andrade 4 Edwaldo Dourado5}

Keywords: classification, epidemiology, odontogenic tumors.

\section{Summary}

\begin{abstract}
$\mathrm{O}$ dontogenic tumors are neoplasms that develops exclusively in the gnathic bones; they originate from odontogenic tissues, by epithelial or mesenchymal proliferation, or both. Aim: To evaluate the incidence of odontogenic tumors in a specific institution, and to compare these findings with other studies in the literature. Study format: A cross-sectional cohort retrospective study. Material and method: The sample was obtained from the files of patients with odontogenic tumors diagnosed between January 1992 and March 2007 (15 years). Cases in which the diagnosis could be adapted to the new World Health Organization (WHO) of 2005 were included. Data such as gender, age, anatomical site, histological type and symptomatology were analyzed. Results: Odontogenic tumors were $4.76 \%$ of all biopsied lesions within the studied period. The mean age was 30.7 years; $57 \%$ of the patients were male. The keratocystic odontogenic tumor was the most prevalent histological type (30\%), followed by the ameloblastoma (23,7\%). The rate of asymptomatic cases was $75.7 \%$. Conclusion: Odontogenic tumors occurred more frequently in females, in the second and third decades of life, and more commonly in the mandible; most cases were asymptomatic.
\end{abstract}

Dental surgeon, resident in buccomaxillofacial surgery and traumatology, Hospital Universitário Oswaldo Cruz.

${ }^{2}$ Dental surgeon, student in the specialization course on buccomaxillofacial surgery and traumatology, Universidade de Pernambuco - FOP/UPE. ${ }^{3}$ Dental surgeon, resident in buccomaxillofacial surgery and traumatology, Hospital Universitário Oswaldo Cruz - HUOC/UPE. ${ }^{4}$ Doctor, adjunct professor of buccal pathology, Faculdade de Odontologia de Pernambuco - Universidade de Pernambuco - FOP/UPE. ${ }_{5}^{5}$ Doctor, adjunct professor of buccomaxillofacial surgery and traumatology, Faculdade de Odontologia de Pernambuco - Universidade de Pernambuco - FOP/UPE. Discipline of buccal pathology, Faculdade de Odontologia da Universidade de Pernambuco - FOP/UPE.

Address for correspondence: Emanuel Sávio de Souza Andrade - Faculdade de Odontologia de Pernambuco, Disciplina de Patologia Bucal. Av. Gal. Newton Cavalcanti 1650 Tabatinga Camaragibe PE 54753-220.

This paper was submitted to the RBORL-SGP (Publishing Manager System) on 10 May 2007. Code 4513.

The article was accepted on 14 July 2007. 


\section{INTRODUCTION}

Odontogenic tumors are a heterogeneous group of lesions with variable clinical and pathohistological features. The biological behavior of these tumors includes hamartomatous proliferation, non-aggressive benign tumors, and aggressive and malignant tumors. ${ }^{1}$ There has been considerable interest in odontogenic tumors by oral pathologists, who have studied and catalogued these tumors for decades. These tumors are $2.5 \%$ of all biopsied lesions in dental offices. ${ }^{2,3}$

Although many retrospective studies have been conducted in Africa, ${ }^{4,5,6}$ Asia, ${ }^{7}$ Europe, ${ }^{8,9}$ and North America, ${ }^{10}$ unanswered question still remain about the relative frequency and the incidence of certain odontogenic tumors. ${ }^{11}$

The geographical distribution of these lesions is variable. ${ }^{2}$ Many studies in different part of the world have shown differences in the relative prevalence of these tumors. ${ }^{12}$ Few reports have been published in English about the frequency of odontogenic tumors in Latin America, particularly in Brazil..$^{13}$ The frequency was $1.29 \%{ }^{14}$ in a Chilean study of 362 cases.

Various attempts at classification of these tumors have been published to define diagnostic criteria, given the diversity of lesions that may arise from odontogenic tissues. 1

The first classification of these tumors was published in 1971, based on a 5-year joint effort coordinated by the World Health Organization (WHO).12 An updated edition of this classification was published in $1992 .{ }^{15}$ A new classi- fication was proposed in 2005, which included the odontogenic keratocyst as a benign odontogenic tumor. ${ }^{16}$

The purpose of this study was to investigate the epidemiological behavior of this heterogeneous group of tumors across a 15-year period (1992-2007) and to compare these data with those in the literature.

\section{MATERIAL AND METHODS}

A retrospective study was made of cases of odontogenic tumors recorded at our institution between January 1992 and March 2007. The variables gender, age, anatomical site, histological type and symptoms were analyzed in 238 histopathology reports.

In reports with recurring tumors, the histological appearance of the first and recurring tumors was compared and considered as a single case.

The diagnoses were reassessed and adapted to the 2005 WHO classification. ${ }^{16}$

After the sample was obtained, a database was generated using the SPSS (v. 13.0) statistics software; the chi-square test was applied to check the statistical significance of the findings. A p value below 0.05 was considered statistically significant.

This study was duly recorded by the Research Ethics Committee of our institution (protocol number 135717/07).

\section{RESULTS}

Patients were distributed according to the data as follows:

Table 1. Distribution of patients according to gender.

\begin{tabular}{|c|c|c|c|c|}
\hline \multirow{3}{*}{ Histological types } & \multicolumn{4}{|c|}{ Gender } \\
\hline & \multicolumn{2}{|c|}{ Male } & \multicolumn{2}{|c|}{ Female } \\
\hline & $\mathrm{N}$ & $\%$ & $\mathrm{n}$ & $\%$ \\
\hline Ameloblastoma & 30 & 52,6 & 27 & 47,4 \\
\hline Cementoblastoma & 1 & 25 & 3 & 75 \\
\hline Keratocystic Odontogenic Tumor & 30 & 43,4 & 39 & 56,6 \\
\hline Calcifying Epithelial Odontogenic Cyst & 7 & 46,6 & 8 & 53,4 \\
\hline Ameloblastic Fibroma & 3 & 75 & 1 & 25 \\
\hline Ameloblastic Fibrodontoma & - & - & 1 & 100 \\
\hline Mixoma & 8 & 53,4 & 7 & 46,6 \\
\hline Odontoma & 17 & 31,4 & 37 & 68,6 \\
\hline Adenomatoid Odontogenic Tumor & 3 & 23 & 10 & 77 \\
\hline Calcifying Epithelial Odontogenic Tumor & 3 & 60 & 2 & 40 \\
\hline Squamous Odontogenic Tumor & - & - & 1 & 100 \\
\hline TOTAL & 102 & & 136 & \\
\hline
\end{tabular}

$p>0,05$ - chi-square test 
Table 2. Age of patients with odontogenic tumors.

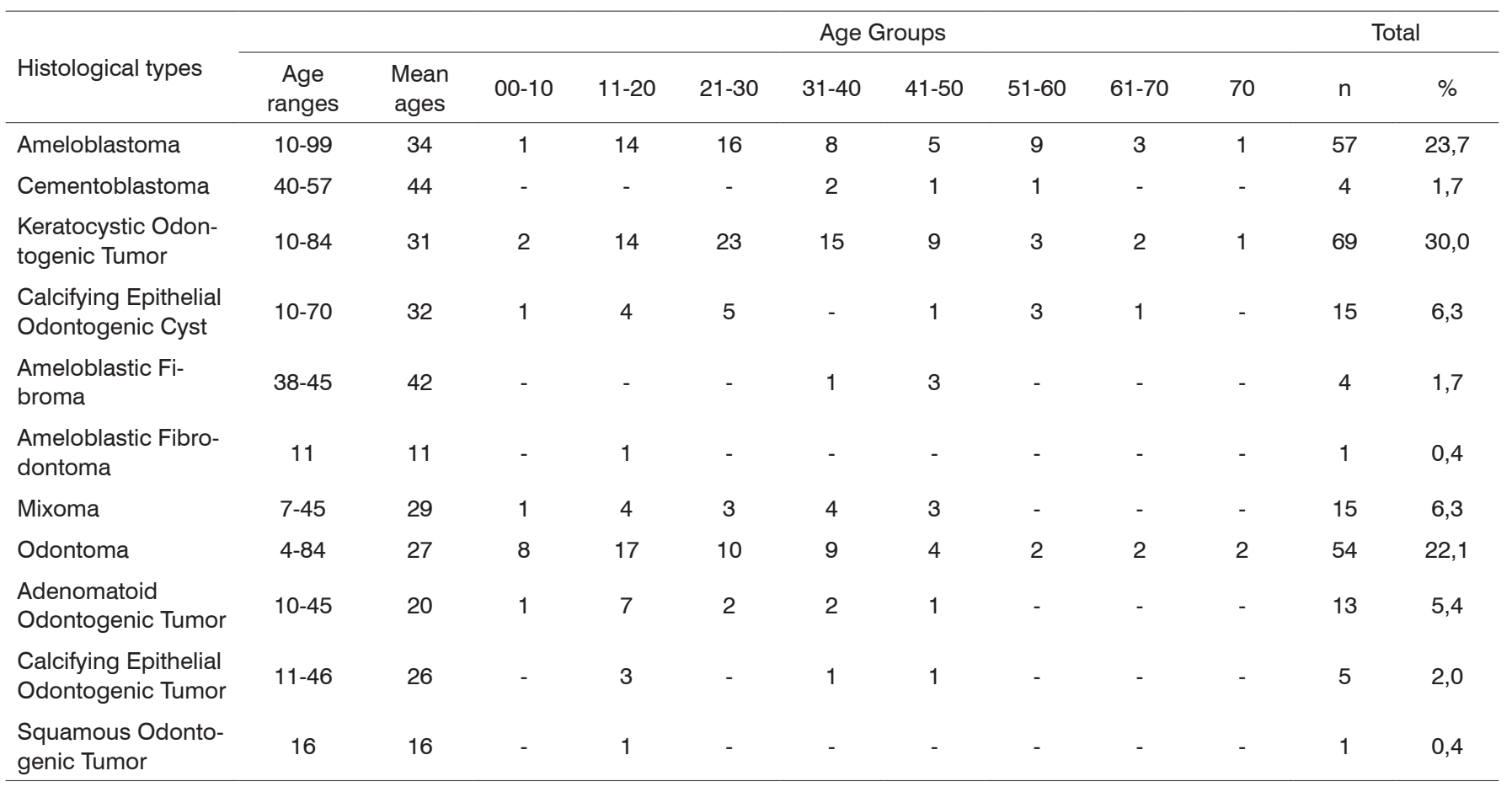

$p>0,05$ - chi-square test

Table 3. Anatomical sites of odontogenic tumors.

\begin{tabular}{|c|c|c|c|c|}
\hline \multirow{3}{*}{ Histological types } & \multicolumn{4}{|c|}{ Anatomical site } \\
\hline & \multicolumn{2}{|c|}{ Mandible } & \multicolumn{2}{|c|}{ Maxilla } \\
\hline & $\mathrm{N}$ & $\%$ & $\mathrm{n}$ & $\%$ \\
\hline Cementoblastoma & 04 & 100 & - & - \\
\hline $\begin{array}{l}\text { Keratocystic Odontogenic } \\
\text { Tumor }\end{array}$ & 52 & 75,3 & 17 & 14,7 \\
\hline Ameloblastic Fibroma & 04 & 100 & - & - \\
\hline $\begin{array}{l}\text { Ameloblastic } \\
\text { Fibrodontoma }\end{array}$ & 01 & 100 & - & - \\
\hline Mixoma & 07 & 46,6 & 08 & 53,4 \\
\hline $\begin{array}{l}\text { Calcifying Epithelial } \\
\text { Odontogenic Tumor }\end{array}$ & 04 & 80 & 01 & 20 \\
\hline $\begin{array}{l}\text { Squamous Odontogenic } \\
\text { Tumor }\end{array}$ & 01 & 100 & - & - \\
\hline TOTAL & 160 & & 78 & \\
\hline
\end{tabular}

$p>0,05$ - chi-square test 
Table 4. Distribution of patients according to symptoms.

\begin{tabular}{|c|c|c|c|c|}
\hline \multirow{3}{*}{ Histological types } & \multicolumn{4}{|c|}{ Symptoms } \\
\hline & \multicolumn{2}{|c|}{ Symptomatic } & \multicolumn{2}{|c|}{ Asymptomatic } \\
\hline & $\mathrm{N}$ & $\%$ & $n$ & $\%$ \\
\hline Cementoblastoma & 2 & 50 & 2 & 50 \\
\hline $\begin{array}{l}\text { Keratocystic Odontogenic } \\
\text { Tumor }\end{array}$ & 20 & 28,9 & 49 & 71,1 \\
\hline Ameloblastic Fibroma & 1 & 25 & 3 & 75 \\
\hline $\begin{array}{l}\text { Ameloblastic Fibrodon- } \\
\text { toma }\end{array}$ & 1 & 100 & - & - \\
\hline Mixoma & 4 & 26,6 & 11 & 73,4 \\
\hline $\begin{array}{l}\text { Calcifying Epithelial } \\
\text { Odontogenic Tumor }\end{array}$ & 1 & 20 & 4 & 80 \\
\hline $\begin{array}{l}\text { Squamous Odontogenic } \\
\text { Tumor }\end{array}$ & 1 & 100 & - & - \\
\hline TOTAL & 58 & & 180 & \\
\hline
\end{tabular}

$p=0,023$ - chi-square test

\section{DISCUSSION}

Odontogenic tumors are infrequent in gnathic bones, and should be included in the differential diagnosis of gnathic bone lesions. ${ }^{2}$ Few published studies have been done on large series in any country or region to assess age, gender and site of odontogenic tumors, based on the 1992 classification of the World Health Organization. $3,6,7,14,17$

As of 2005, a new classification included the odontogenic keratocyst as one of the odontogenic tumors, renaming it as a keratocystic odontogenic tumor. This was the most prevalent lesion in this study (30\%) (Table 2 ); given its recent reclassification, it was not possible to compare its prevalence with that of other odontogenic tumors or with findings published elsewhere. The incidence was slightly higher in females (Table 1); this finding has not been demonstrated in other studies, such as that by Mosqueda-Taylor et al. ${ }^{18}$ There were two age-related peaks in both genders; the highest peak was in the second and third decades of life, and a lower peak occurred in the seventh decade of life (Table 2). These findings are similar to those of Ahlfors et al. ${ }^{19}$

The ameloblastoma was the second most common tumor in this study (23.7\%) (Table 2); its frequency was lower compared to published reports by Lu et al. ${ }^{7}(59 \%)$, Oduyoka6 (58\%) and Adebayo et al. ${ }^{5}$ (48\%). The amelo- blastoma is considered as the most common histological type in Africa, followed by the odontogenic mixoma. ${ }^{6,15}$ In countries like Chile ${ }^{18}$ and Canadá, ${ }^{10}$ they are respectively 20 and 18\% of such tumors; the most frequent tumor in these countries is the odontoma (Chile - 45 and Canada - 46\%). ${ }^{10,19}$ In our study, the frequency of ameloblastoma was higher in males $(52.6 \%)$ (Table 1 ), as also seen in studies conducted in Nigeria5 and Turkey; ${ }^{8}$ most of these patients had no tumor-related symptoms $(79 \% ; \mathrm{p}=0.023)$ (Table 4). Findings in African studies have shown that the prevalence of this tumor is higher in the second to fourth decades of life,,, 17 and that they are located preferably in the mandible, ${ }^{7,17}$ both of which were confirmed in our study (Tables 2 and 3 ).

Odontomas are $4 \%$ to $67 \%$ of odontogenic tumors. $5,6,10$ This was the most common of these tumors in the Americas, as reported by Ochsenius et al., ${ }^{14}$ MosquedaTaylor et al., ${ }^{13}$ and Daley et al. $;^{10}$ odontomas are least frequent in Africans ${ }^{6}$ and Chinese. ${ }^{7}$ There were 54 cases of odontomas in our 15-year study (22.1\%) (Table 2). The lower incidence of odontomas in Africans ${ }^{4}$ is due probably to the lack of symptoms of many of these lesions ${ }^{6}$ or by genetic factors. This neoplasm was diagnosed mostly in patients aged below 30 years; published papers have reported that new odontomas are discovered up to the third decade of life. ${ }^{5,6}$ Odontomas were more prevalent in the 
maxilla (57.5\%) (Table 3) and in females (68.6\%) (Table 1 ); this is similar to the findings of Santos et al. ${ }^{13}$

The incidence of the odontogenic mixoma was 6.3\% of all odontogenic tumors in our study (Table 2), which is about two times less than that reported by MosquedaTaylor et al., ${ }^{3}$ but comparable to North-American studies. ${ }^{10}$ Our study revealed a slightly higher prevalence of this tumor in males (Table 1); Ladeinde et al. ${ }^{12}$ and Odukoia et $a .^{6}$ have reported a higher frequency in females. This study showed that the mean age of these patients was 29 years, higher than the age reported in two previous studies in Nigeria ${ }^{5}$ and Mexico, ${ }^{11}$ in which the mean age was 19 years. A slight preference for the maxilla (53.4\%) (Table 3) has been reported in a number of studies, such as those by Mosqueda-Taylor et al., ${ }^{3}$ Lu et al., ${ }^{7}$ on the other hand, have reported differently.

The incidence of the adenomatoid odontogenic tumor was $5.4 \%$ of all odontogenic tumors in our study (Table 2). Some papers have reported that this tumor is more frequently found in the maxilla ${ }^{4,13,17}$ and in female patients. ${ }^{17}$ (Table 1); these findings were confirmed in our study, in which $53.9 \%$ of these lesions were found in the maxilla (Table 3 ) and $77 \%$ of these patients were female (Table 1), mostly in the second decade of life (7 of 13 cases) (Table 2).

The calcifying epithelial odontogenic cyst was seen in 15 cases (6.3\%) (Table 2); there was a slightly higher incidence in females (53.4\%) (Table 1), and 66\% of these cases were in the mandible (Table 3 ). These findings are similar to those in most studies ${ }^{13}$ except for Hiroyuki et al.'s $1^{7}$ report. This neoplasm is usually found accidentally in routine exams. 5 In our study, $80 \%$ of these cases were asymptomatic $(\mathrm{p}=0.023)$ (Table 4$)$ and showed no age preference (Table 2 ).

The incidence of the ameloblastic fibroma and the cementoblastoma was $1.7 \%$ each, and the incidence of the calcifying epithelial odontogenic tumor was $2 \%$ of the odontogenic tumors in our study (Table 2). The cementoblastoma was more frequent in females (75\%) (Table 1); the ameloblastic fibroma was more frequent in males (75\%) (Table 1), as was the calcifying epithelial odontogenic tumor $(60 \%)$ (Table 1). These lesions were more frequent in the mandible in our study (Table 3), contrary to some studies that have reported a higher frequency these tumors in the maxilla. ${ }^{13}$

Lesions such as the squamous odontogenic tumor and the ameloblastic fibrodontoma were found in a single case each; both were females and presented mandibular pain. Our study confirmed the low frequency of these neoplasms as shown in other studies, ${ }^{3,7,12,14}$ which underlines their rarity.

It is essential to define the epidemiology of these tumors to improve our knowledge about their behavior, which allows us to optimize the diagnosis and therapy.

\section{CONCLUSION}

There is a slight predominance of odontogenic tumors in women and during the first decades of life; most of them occur in the mandible, and most are asymptomatic. There were statistically significant differences among the variables histological type and symptoms.

In Brazil, specifically in this study, which was done in a region where population miscegenation is significant, there were some differences compared to published studies undertaken in other parts of the world.

\section{REFERENCES}

1. Buchner A, Merrell PW, Carpenter WM. Relative frequency of central odontogenic tumors: a study of 1,088 cases from Northern California and comparison to studies from other parts of the world. J Oral Maxillofac Surg 2006;64(9):1343-52.

2. Antunes AA, Silva JL, Silva PV, Antunes AP. Tumores odontogênicos: Análise de 128 casos. Rev Bras Cir Cabeça Pescoço 2006;35(3):160-3.

3. Mosqueda-Taylor A, Ledesma-Montes C, Caballero-Sandoval S, Portilla-Robertson J, Ruíz-Godoy Rivera LM, Meneses-García A. Odontogenic tumors in Mexico: A collaborative retrospective study of 349 cases. Oral Surg Oral Med Oral Pathol Oral Radiol Endod 1997;84(6):672-5.

4. Arotiba JT,Ogunbiyi JO,Obiechina AE. Odontogenic tumours: A 15-year review from Ibadan, Nigeria.Br J Oral Maxillofac Surg 1997;35(5):363-7.

5. Adebayo ET, Ajike SO, Adekeye EO. A review of 318 odontogenic tumors in Kaduna, Nigeria.J Oral Maxillofac Surg 2005;63(6):811-9.

6. Odukoya O. Odontogenic tumors: Analysis of 289 Nigerian cases.J Oral Pathol Med 1995;24(10):454-7.

7. Lu Y,Xuan M,Takata T,Wang C,He Z,Zhou Z et al. Odontogenic tumors: A demographic study of 759 cases in a Chinese populationOra Surg Oral Med Oral Pathol Oral Radiol Endod 1998;86(6):707-14.

8. Olgac V, Koseoglu BG, Aksakalli N. Odontogenic tumours in Istanbul: 527 cases.Br J Oral Maxillofac Surg 2006;44(5):386-8.

9. Tamme T, Soots M, Kulla A, Karu K, Hanstein S-M, Sokk A et al. Odontogenic tumours, a collaborative retrospective study of 75 cases covering more than 25 years from Estonia. J CranioMaxillofac Surg 2004;32(3):161-5.

10. Daley TD,Wysocki GP,Pringle GA. Relative incidence of odontogenic tumors and oral and jaw cysts in a Canadian population.Oral Surg Oral Med Oral Pathol 1994;77(3):276-80.

11. Simon ENM, Merkx MAW, Vuhahula E, Ngassapa D, Stoelinga PJW. A 4-year prospective study on epidemiology and clinicopathological presentation of odontogenic tumors in Tanzania.Oral Surg Oral Med Oral Pathol Oral Radiol Endod 2005;99(5):598-602.

12. Ladeinde AL, Ajayi OF, Ogunlewe MO, Adeyemo WL, Arotiba GT, Bamgbose BO et al.. Odontogenic tumors: A review of 319 cases in a Nigerian teaching hospital. Oral Surg Oral Med Oral Pathol Oral Radiol Endod 2005;99(2):191-5.

13. Santos JN, Pinto LP, Figueiredo CRLV, Souza LB. Odontogenic tumors - Analysis of 127 cases. Pesqui Odontol Bras 2001;15(4):308-13.

14. Ochsenius G,Ortega A,Godoy L,Peñafiel C,Escobar E. Odontogenic tumors in Chile: A study of 362 cases.J Oral Pathol Med 2002; 31(7):415-20.

15. Kramer IRH, Pindborg JJ, Shear M. WHO histological typing of odontogenic tumours. 2nd ed. Geneva: Springer-Verlag; 1992.

16. Barnes L, Everson J, Reichart P. World Health Organization Classification of Tumours: Pathology and Genetics of Tumours of the Head and Neck. Lyon, France, International Agency for Research on Cancer, 2005. 
17. Hiroyuki O, Hirotsugu Y, Tilakaratne WM, Odontogenic Tumors in Sri Lanka: Analysis of 226 Cases. J Oral Maxillofac Surg 2007;65:875882.

18. Mosqueda Taylor A, Irigoyen Camacho ME, Díaz Franco MA, To $7 r r e s$ Tejero MA. Odontogenic cysts. Analysis of 856 cases. Med Oral 2002;7:89-96.
19. Ahlfors E, Larsson A, Sjögren S. The Odontogenic keratocyst: A benign cystic tumor. J Oral Maxillofac Surg 1984;42(1):10-9. 